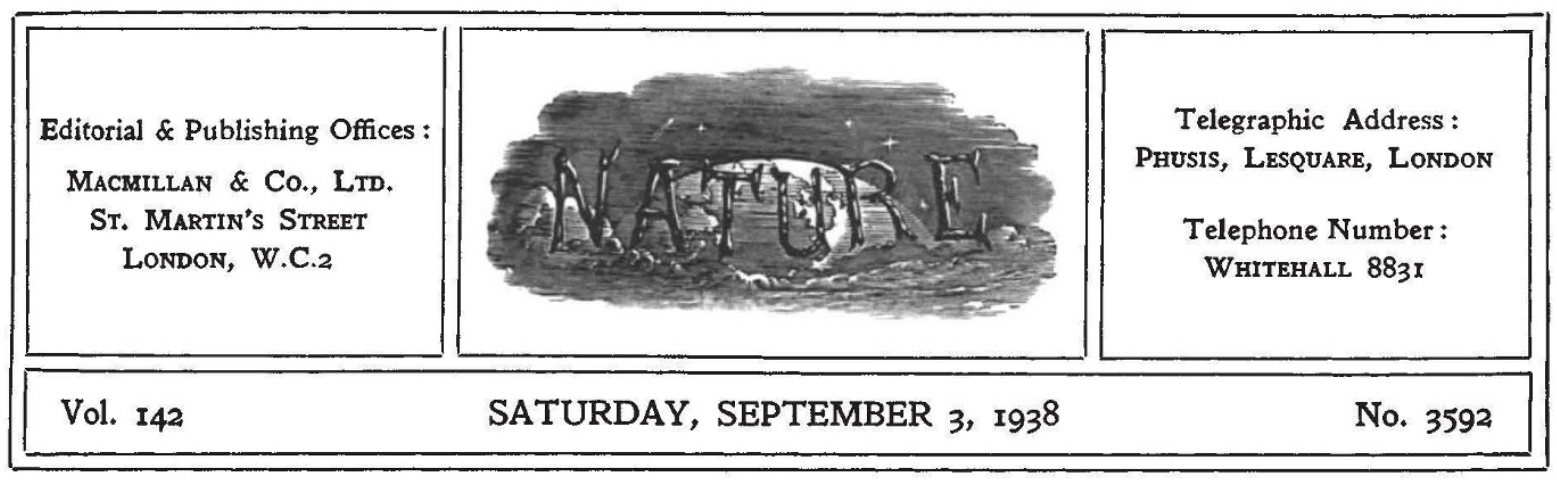

\title{
Co-operation between the British and American Associations
}

TT is probable that Lord Rayleigh's term of office will mark one of the most momentous periods in the long history of the British Association. To take the initiative in forming a Division to deal with the social and international relations of science is to undertake an onerous and responsible task for which the Association is peculiarly fitted, and in which it will have the good wishes of all who realize the effect that advances in science may have, for good or ill, on the welfare of our own community and of the nations of the world at large. As the Council of the Association does not meet until November, the General Committee, at its final meeting at Cambridge, approved the appointment of a provisional committee, and a few possible members of this committee were suggested to be invited to serve upon it. The publication of a list of the names of these members as forming even a provisional com. mittee is, however, premature and unauthorized.

The Cambridge meeting has been signalized by yet another advance of international importance. The American Association for the Advancement of Science has aims and interests which have much in common with those of the British Association, and it has long been felt that a closer liaison between the two Associations would hasten the realization of those ideals of international cooperation and good will, and would form a very considerable contribution made by men of science to the cause of world peace.

By a happy chance, the principal officers of the American Association were able to be present at the Cambridge meeting of the British Association, and they have agreed to transmit to their executive two suggestions, which have the full approval of the General Committee of the British Association, for promoting a closer union between the two
Associations. It is suggested that, in alternate years, a distinguished American man of science should be invited to deliver an address before the members of the British Association at their annual meeting, and reciprocally, in the years not marked by such lectures, that a distinguished British scientific worker should address the members of the American Association at their summer meeting.

These addresses, which will be devoted to a topic of broad scientific interest, will usually, but not necessarily, deal with some of those aspects of science and society which are the concern of the new Division of the British Association.

Further, the officers of the Associations are anxious that the Associations, through their members, should have more intimate knowledge, each of the other's work. As a beginning to that end, it is suggested that a number of those actively engaged in the work of either Association, as members of Council or otherwise, should be elected to membership of the sister Association, with the full privileges of attendance at meetings and of reception of journals.

This principle of exchange of the privileges of membership may be greatly extended in the future; but, in this connexion much will depend on the form taken by the new quarterly journal which will replace the present annual report of the British Association after the publication of the report of the Cambridge meeting.

The Associations are to be warmly congratulated on their courage and initiative in taking these steps, steps which are obviously but the beginnings of others which will lead to greater understanding and closer co-operation, with corresponding repercussions on the friendship between two great democratic communities. 